\title{
Biopsy of Prostate
}

National Cancer Institute

\section{Source}

National Cancer Institute. Biopsy of Prostate. NCI Thesaurus. Code C51701.

Removal of tissue from the prostate for microscopic examination. 